active immunity by using pigs previously injected with variable amounts of swine fever antivirus immunoglobins.

The vaccine used was an attenuated strain of swine fever virus : the Thiverval Strain. The immune response was estimated as follows :

- by the kinetics of appearance of the neutralizing serum antibodies, studied by means at seroneutralization in cell culture;

- by resistance of the pigs after challenge with the virulent strain.

Vaccination per parenteral route with $\mathrm{IO}^{4} \mathrm{UFP}$ of the thermosensitive strain was compared with that performed per intranasal route using $10^{5} \mathrm{UFP}$ of the same strain.

The results obtained were the following:

I. In the absence of passive immunity :

the immune response of the pigs was the same whatever the route of administration of the vaccine : early, intense and long lasting.

2. In the presence of passive immunity of low intensity :

at the moment of the primary response, the production of neutralizing antibodies was partly inhibited. However, the animals resisted to the challenge with the virulent strain.

3. In the presence of passive immunity of high intensity :

At the moment of the primary response, production of antibodies was entirely inhibited. A large proportion of the animals resisted to the challenge with the virulent strain, practised at a period when the passive antibodies had disappeared.

The kinetics of appearance of neutralizing antibodies of the secundary type showed that this resistance was due to an active immunization.

\title{
Swine fever vaccination of piglets in naiural conditions with the " Thiverval " strain in presence of colostrum derived passive immunity
}

\author{
M. LAUNAIS and J. M. AYNAUD
}

Laboratoire de Pathologie porcine, I. N. R. A., 78850 Thiverval-Grignon

The "Thiverval " strain is a cold mutant of swinc fever isolated in tissue culture at $29-30^{\circ} \mathrm{C}$. Because of its immunizing properties and its innocuity, this strain is used as live vaccine. I 42 piglets born from sows immunized or not against swine fever several months ago, were vaccinated with Thiverval strain in natural conditions between the Ioth and goth day of life using per nasal, per os or intramuscular route. The colostrum derived passive immunity and the active immunity induced by vaccination were determined by means of challenge with virulent Alfort strain and by means of titration in tissue culture of specific neutralizing antibodies of serum. Seroneutralizations were made in cell cultures by means of immunofluorescent techniques.

In absence of passive immunity, vaccination performed in 18 days old piglets was efficient. In piglets from immune sows, vaccination was unefficient on days Io, I 3 and 28 of life, because of the too high level of passive immunity. But on day $4^{6}$, active immunization became possible. Piglets were protected against virulent infection (challenge) on days 54-55 of life. Results from 
these experiments suggest that a particular period exists around the 30 th and 6oth day of life of piglets having passive immunity. During this period, maternal passive immunity protects piglets against virulent infections, but also allows induction of active immunity following vaccination with live vaccine. New investigations are needed to determine limits and characteristics of this period.

\title{
Immune response in piglets. The effect of speeific passive immunity on immune response against an inert antigen, hen egg-white lysozyme
}

\author{
P. ROUZE, M. HOUDAYER and J. J. METZGER* \\ Laboratoive de Pathologie Porcine, I. N. R. A., \\ y8850 Thiverval-Grignon \\ * Station d'Immunologie et de Virologie
}

In previous reports, we already showed that piglets have been actively immunized with lysozyme in the presence of specific antibodies acquired by the colostral way or by intraperitoneal injection. The purpose of this new cxperiment, realized without any adjuvant was to study the role of this parameter. In these conditions the injection of increasing doses of lysozyme, even in the absence of any specific antibody, stimulated a less efficient immunization. This active immunity was inhibited by rather low passive antiborly amounts. This result led us to define the passive antibody threshold beyond which lysozyme antigenic stimulation was ineffective and to show that its level was lowered in the absence of adjuvant. In this paper, the practical implication of this threshold concept is discussed.

In the same experiment, we compared the effect of the stimulation with a living and an inert antigen, namely hog-cholera virus vaccine and lysozyme, in passively immune animals. We observed a narrow parallelism between these two systems. It appeared, at last, that the challenge performed with the fully virulent Alfort strain of Swine fever virus led to an immunodepression which tends to be suppressed by the vaccination.

\section{Respiratory disease syndroms in the young pig. Pathogenic properties of Ascaris suum}

\author{
J. P. RAYNAUD, A BOUCHET and G. BRUNAULT \\ Station de Recherches et Développement vétérinaire, \\ Pfizer International, \\ B. P. 42, 37400 Amboise (France)
}

The pathogenic properties of $A$ scaris suttm were checked on mice and an attempt was made to determine the dose which given to swine is not able to cause any rise in the blood level of eosinophilic cells.

- Embryonated eggs can easily give respiratory symptoms in young pigs of $15 \mathrm{~kg}$ b.w. Even 